levels and climate change increased carbon uptake by around 80 million tonnes per year, whereas fire and landuse change boosted carbon emissions by an average of 44 million tonnes per year. In addition, Australia exported 1.5 times more carbon in fossil fuels than it consumed over the two decades, and 2.5 times more from 2009 to 2010. Biogeosciences 10, 851-869 (2013)

\section{MICROBIOLOGY}

\section{Healthier} prehistoric plaque

When humans turned to agriculture, and later to modern starch- and sugar-filled diets, the microbes colonizing their teeth changed drastically.

Alan Cooper at the University of Adelaide, Australia, and his colleagues sequenced microbial DNA from the calcified dental plaque (pictured) of 34 mesolithic to medieval human skeletons. The oral microbial populations of individuals who lived in early farming communities were much less diverse than those of hunter-gatherers, and harboured more bacteria linked to diseases such as gingivitis.

Contemporary microbial populations are, in turn, less diverse than those of earlier communities and are dominated by bacteria linked to diseases such as those that cause cavities. The authors believe that the recent shift probably occurred during the Industrial Revolution, when processed sugar and flour became widely available.

Nature Genet. http://dx.doi. org/10.1038/ng.2536 (2013)

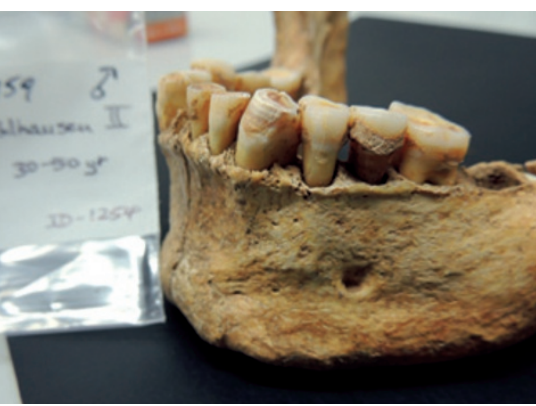

\section{Flower power guides bees}

Along with colour and scent, electrical fields on flowers can guide bees' search for pollen and nectar.

Flowers often have a negative charge, whereas insects such as bumblebees (Bombus terrestris) tend to build up a positive charge as they fly. Daniel Robert and his colleagues at the University of Bristol, UK, placed electrodes in stems of petunias (Petunia integrifolia) and found that visits from bumblebees changed the flowers' electrical potential for a short time. The bees
COMMUNITY CHOICE

\title{
Lonely teen rats choose drugs
}

\section{A HIGHLY READ \\ on www.cell.com/ neuron in February}

Socially isolated adolescent rats acquire amphetamine- and alcohol-associated memories faster - and in the case of amphetamine are slower to extinguish, or 'unlearn', them - than rats kept in groups.

Hitoshi Morikawa and his colleagues at the University of Texas at Austin found that isolated rats formed a preference for drug-associated stimuli after only one exposure, whereas rats housed in groups required repeated exposures. The researchers also showed that social isolation boosted signalling by certain neurons in a part of the brain that links behaviours with rewards. This boost was not reversed by returning the rats to a social environment.

Such effects may help to explain how pre-adult experiences can increase vulnerability to addiction, the authors suggest.

Neuron 77, 335-345 (2013)

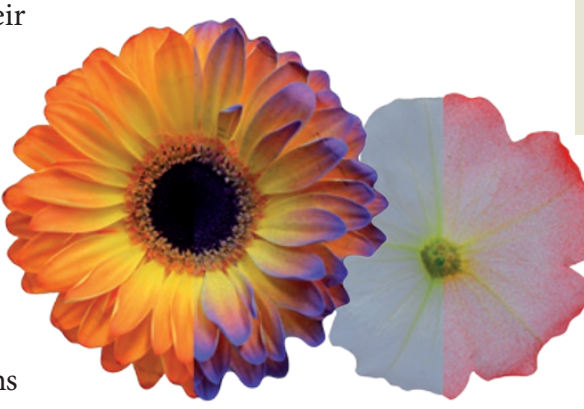

could sense such electrical cues and use them to recognize and remember which flowers provided them with a reward. Coating the flowers with coloured, charged particles (pictured) showed that the floral electrical fields were strongest at the outer edges of petals.

Electrical signals could be a particularly versatile way for plants and pollinators to communicate, the authors say. Science http://dx.doi.

org/10.1126/science.1230883 (2013)

For a longer story on this research, see go.nature.com/nvjbli

\section{HOLOGRAPHY}

\section{Liquid crystal movies}

Holographic technology can produce three-dimensional images that can be seen without special eyewear and without causing visual fatigue, but the images are usually static.
Takeo Sasaki and his colleagues at Tokyo University of Science used liquid crystals made from organic compounds to produce a dynamic hologram. An electrical field applied to the liquid-crystal mixture alters how this medium bends, or refracts, the direction of incoming light. The researchers sent coupled laser beams through the crystal mixture to generate a holographic image.

Although small and monochromatic, the hologram exhibited more than seven times the light amplification of previous attempts, and refreshed every 8 milliseconds — fast enough to produce a smooth holographic movie. Such a technique could be used for three-dimensional displays. Appl. Phys. Lett. 102, 063306 (2013)

\section{ANIMAL BEHAVIOUR}

\section{How monarchs know where to go}

Migrating butterflies may use temperature to choose their flight direction.

Each autumn, monarch butterflies (Danaus plexippus) migrate more than 3,200 kilometres down eastern North America to overwinter in Mexico. The insects navigate by internal clocks that are calibrated by sunlight. But what halts the journey south? The answer is the cold.

Steven Reppert and Patrick Guerra of the University of Massachusetts Medical School in Worcester caught butterflies at the beginning of the autumn migration and kept them in the chilly temperatures that they would experience at sites in the mountains of central Mexico. When released after 24 days in the cold, the butterflies flew off northward, the direction they would normally take in spring. Simulating changes in day length did not have this effect.

Worryingly, if climate change obscures the cold signal, butterflies may keep flying south and not know when to return.

Curr. Biol. http://dx.doi. org/10.1016/j.cub.2013.01.052 (2013)

\section{$\rightarrow$ NATURE,COM}

For the latest research published by Naturevisit:

www.nature,com/latestresearch 